\title{
Interactive comment on "Evaluation of Southern Ocean cloud in the HadGEM3 general circulation model and MERRA-2 reanalysis using ship-based observations” by Peter Kuma et al.
}

\section{Peter Kuma et al.}

pku33@uclive.ac.nz

Received and published: 21 September 2019

The response to referees is contained in the supplement.

Please also note the supplement to this comment: https://www.atmos-chem-phys-discuss.net/acp-2019-201/acp-2019-201-AC1supplement.pdf 2019. 